\title{
Hubungan Promosi Jabatan dengan Peningkatan Kinerja Pegawai Pada Bagian Kepegawaian Pemerintah Daerah Provinsi Lampung
}

\author{
Fahrizi $^{1 *}$, Trisnowati Josiah ${ }^{1}$, Yulina ${ }^{1}$ \\ ${ }^{1}$ Universitas Sang Bumi Ruwa Jurai \\ *Correspondence : fahrizi431@gmail.com
}

\begin{abstract}
Abstrak.
Promosi jabatan merupakan sarana yang dapat mendorong pegawai untuk lebih baik atau lebih bersemangat dalam melakukan suatu pekerjaan dalam lingkungan organisasi. Tujuan penelitian ini adalah untuk melihat adanya hubungan antara promosi jabatan dengan peningkatan kinerja pegawai pada bagian kepegawaian Pemerintah Daerah Provinsi Lampung. Penelitian ini adalah penelitian kuantitatif deskriptif dengan sampel 40 responden. Berdasarkan hasil Uji-t didapatkan bahwa ada hubungan positif antara promosi jabatan dengan peningkatan kinerja pegawai pada Bagian Kepegawaian Pemda Provinsi Lampung. Hasil analisis data menunjukkan korelasi Product Moment antara fasilitas kerja dengan kualitas kerja 0,340 ( $\mathrm{r}_{\text {hitung }}$ ). Dan harga koefisien determinasi $\left(\mathrm{r}^{2}\right)$ sebesar 0,116 . Kemudian hasil tersebut dikonsultasikan dengan dengan rtabel dengan taraf signifikansi 5\% untuk menguji taraf signifikasinya. Harga koefisien korelasi pada $\mathrm{r}_{\text {tabel }}$ dengan taraf signifikansi $5 \%$ dan $\mathrm{N}=40$ adalah 0,297 hasil ini menunjukkan bahwa $\mathrm{r}_{\text {hitung }}$ lebih besar dari $\mathrm{r}_{\text {tabel. }}$. Dengan demikian terdapat hubungan positif dan signifikan antara promosi jabatan dengan peningkatan kinerja, berarti semakin tinggi promosi jabatan maka semakin tinggi pula peningkatan kinerja yang ada.
\end{abstract}

Kata kunci: Promosi Jabatan, Peningkatan Kinerja, Kepegawaian, Pemerintah Daerah

\begin{abstract}
.
Promotion is a means that can encourage employees to be better or more enthusiastic in doing a job in an organizational environment. The purpose of this study was to see the relationship between promotions and improving employee performance in the staffing section of the Lampung Provincial Government. This research is a descriptive quantitative research with a sample of 40 respondents. Based on the results of the $t$-test, it was found that there was a positive relationship between promotion and employee performance improvement at the Lampung Provincial Government Personnel Section. The results of data analysis show the Product Moment correlation between work facilities and work quality of $0.340\left(r_{\text {count }}\right)$. And the price of the coefficient of determination $\left(r^{2}\right)$ is 0.116 . Then the results were consulted with the $r_{\text {table }}$ with a significance level of $5 \%$ to test the significance level. The price of the correlation coefficient on $r_{\text {table }}$ with a significance level of $5 \%$ and $N=40$ is 0.297 . This result shows that $r_{\text {count }}$ is greater than $r_{\text {table. }}$ Thus, there is a positive and significant relationship between promotion and performance improvement, meaning that the higher the promotion, the higher the existing performance improvement.
\end{abstract}

Keywords: Position Promotion, Performance Improvement, Staffing, Local Government

\section{PENDAHULUAN}

Sumber Daya Manusia merupakan faktor yang sangat penting dalam sebuah organisasi dengan skala besar maupun kecil (Dahlan et al., 2017), baik yang bergerak dalam bidang pengadaan barang/jasa (Marlinda \& Devitra, 2020). Setiap organisasi pemerintah maupun swasta dituntut bekerja lebih cepat, tepat, mudah, efektif dan efisien (Nasution, 2019). Oleh karena itu, ketertiban tenaga kerja dalam aktifitas perusahaan perlu dilengkapi kemampuan dalam hal pengetahuan maupun keterampilan (Andriani, 2018). Merupakan prioritas utama dalam pengelolaannya agar pemanfaatan sesuai dengan yang diharapkan oleh instansi, organisasi atau perusahaan 
tersebut dalam usaha mencapai tujuan yang telah ditetapkan (Arifudin et al., 2017).

Untuk mempertahankan eksistensi kerja, sebuah organisasi dituntut pengembangan kualitas sumber daya (Sudarsana, 2016) di semua komponen yang ada di organisasi tersebut. Kompetensi sumber daya manusia dalam organisasi harus dapat dioptimalkan (Ghozali et al., 2020) dengan baik agar dapat menciptakan iklim kerja yang kondusif dan target kerja yang diinginkan tercapai (Lungguh Perceka, 2018). Hal tersebut tidaklah mudah untuk dijalankan, diperlukan pemahaman yang baik tentang sebuah organisasi dan diperlukan sebuah strategi pengembangan yang matang agar sumber daya manusia dapat digunakan sesuai dengan yang dibutuhkan oleh sebuah organisasi atau sebuah instansi.

Berbagai cara dapat dilakukan untuk melakukan pengembangan sumber daya manusia, salah-satunya adalah dengan melalui promosi Jabatan (Animun et al., 2017). Dengan promosi jabatan diharapkan pegawai akan merasa dihargai, diperhatikan, dibutuhkan dan diakui kemampuan kerjanya oleh atasan sehingga mereka akan menghasilkan keluaran (output) yang tinggi (Hasibuan et al., 2021). Promosi jabatan dilaksanakan untuk mengoptimalkan sumber daya manusia yang dimiliki organisasi, selain itu promosi jabatan bertujuan untuk meregenerasi sumber daya manusia dalam organisasi demi kelangsungan organisasi tersebut. Penilaian kinerja terhadap pegawai merupakan tolak ukur utama dalam pengembangan SDM (Haryadi et al., 2022).

Adanya promosi jabatan dalam organisasi/instansi pada dasarnya bertujuan memotivasi pegawai agar meningkatkan prestasi kerjanya. Pegawai yang mendapat promosi jabatan harus memenuhi kriteriakriteria yang telah ditentukan sehingga dapat mempermudah promosi jabatannya bagi pegawai tersebut (Wardhani \& Harjito, 2020). Dengan adanya promosi jabatan maka jenjang karir yang diinginkan oleh seorang pegawai akan tercapai dan terpenuhi keinginannya. Setiap pegawai yang mempunyai dan merasa prestasi kerjanya tinggi sangat mendambakan promosi jabatan, karena dipandang sebagai penghargaan atas keberhasilannya menunjukan kinerja yang tinggi sekaligus sebagai pengakuan atas kemampuan dan potensi pegawai yang bersangkutan untuk menduduki posisi yang lebih tinggi dalam perusahaan. Selain itu, promosi jabatan dapat dikatakan sebagai wujud perhatian dari perusahaan sehingga dari sini dapat diharapkan semangat kerja yang tinggi tetap terpelihara (Rahayu, 2017).

Keputusan promosi pada umumnya didasarkan atas senioritas keunggulan kualitas kerja (Rapareni, 2020), namun tidak menjamin kompetensi yang dimiliki sesuai dengan yang ada di lapangan. Promosi jabatan seperti pedang bermata dua bila dikerjakan dengan baik maka akan menjadi sarana dalam pemecahan berbagai masalah tetapi apabila tidak dikerjakan dengan benar maka akan menimbulkan ketidakpuasan atau perselisihan diantara para pegawainya dan menjadikan pegawai kurang memiliki loyalitas.

Dengan penilaian kinerja maka atasan dapat mengetahui seberapa mampu pegawai mengerjakan tugas dan tanggung jawab yang diberikan kepadanya, dengan demikian sebuah organisasi atau instansi dapat menentukan balas jasa yang layak baginya. Dalam penilaian kinerja sering muncul berbagai permasalahan salahsatunya adalah tidak semua penilaian sesuai dari semua situasi dan kondisi nyata (Andriani, 2018; Animun et al., 2017; Rahayu, 2017).

Melalui mekanisme penilaian kinerja akan diketahui seberapa baik pegawai telah melaksanakan tugas-tugas yang diberikan kepadanya. Penilaian kinerja juga dapat digunakan perusahaan untuk mengetahui kekurangan dan potensi seorang karyawan (Nurlina, 2020). Dari hasil tersebut, sebuah organisasi atau instansi dapat mengembangkan suatu perencanaan sumber daya manusia secara menyeluruh dalam 
menghadapi masa depan institusi. Perencanaan sumber daya manusia secara menyeluruh tersebut berupa jalur-jalur karir atau promosi-promosi jabatan para pegawainya (Ananda, 2019).

Penjelasan di atas terlihat dari masih banyak kesalahan kerja yang dilakukan pegawai dalam bekerja seperti pekerjaan yang tidak dapat diselesaikan tepat pada waktunya, karena faktor penunjang untuk hal tersebut tidak mendukung. Hal lain yang dapat terlihat adalah kerjasama antara pegawai dianggap masih rendah, pegawai cenderung jalan sendirisendiri dan kurang memperhatikan pekerjaan teman sejawat (Yusuf, 2018). selain itu semangat kerja yang rendah (Manihuruk \& Tirtayasa, 2020) karena masa kerja pegawai yang cukup lama (Muhamad Ridwan et al., 2018) tetapi tidak ada peningkatan kinerja atau mungkin naik jabatan dan lain sebagainya, hal inilah yang menyebabkan semangat kerja pegawai menurun atau rendah.

Di Pemerintah Daerah Provinsi Lampung saat ini kinerja pegawainya kurang maksimal, walaupun tidak semua pegawai tetapi sebagian besar dari pegawai tersebut selalu melakukan pekerjaannya tidak maksimal dan tidak menyelesaikannya dengan tepat waktu, kerjasama antar pegawai pun kurang maksimal dikarenakan ego masing-masing pegawai dan tidak ada rasa kebersamaan dalam menyelesaikan tugas yang diberikan oleh pimpinan. Oleh karena itu promosi jabatan menjadi salah satu sarana untuk lebih meningkatkan kinerja pegawai pemerintah daerah Provinsi Lampung.

Bagi setiap pegawai, promosi dianggap penting. Pegawai akan merasa dengan promosi ada kepercayaan dan pengakuan mengenai keahlian dan kemampuan juga kecakapan yang dimiliki oleh pegawai tersebut untuk menduduki suatu jabatan yang lebih tinggi. promosi akan memberikan status sosial, wewenang (Authority), tanggung jawab (Responsibility), serta penghasilan (Outcomes)(Setiawan, 2018). Promosi jabatan pada suatu instansi/organisasi berperan dalam menarik minat bagi pegawai tersebut untuk bekerja di instansi tersebut, sehingga proses pengadaan pegawai akan lebih mudah karena banyak peminatnya.

Dari penjelasan di atas dapat disimpulkan bahwa perusahaan harus selektif memilih pegawai sesuai kualifikasi potensi kemampuan serta pengalaman jangka waktu masa bakti yang akan dipromosikan (Hermawan et al., 2020). Karena pegawai yang dipromosikan harus benar-benar pegawai yang memiliki kemampuan serta pengalaman yang memadai agar tugas, wewenang dan jabatan yang lebih tinggi yang akan di tanggungnya dapat terlaksana dengan baik. Promosi jabatan yang baik hendaknya diserahkan kepada pegawai yang memiliki kemampuan dan pengalaman yang lebih tinggi dari pegawai lain. Untuk mendapatkan pegawai yang layak memperoleh promosi jabatan, perusahaan harus menetapkan syarat-syarat bagi pegawai untuk memperoleh promosi jabatan, sehingga promosi jabatan yang dilakukan diberikan kepada pegawai yang tepat. Syarat promosi jabatan pada setiap perusahaan berbeda-beda, sesuai dengan kebijakan perusahaan masing-masing.

Definisi kinerja adalah kemampuan atau hasil kerja seseorang baik secara kualitatif maupun kuantitatif dalam menyelesaikan pekerjaannya sesuai dengan tugas, wewenang dan tanggungjawabnya pada suatu perusahaan. Penilaian kinerja merupakan sebuah proses dimana kinerja individual seorang pegawai diukur dan dievaluasi. Dengan adanya penilaian kinerja maka perusahaan dapat mengetahui seberapa baik pekerjaan yang telah dilaksanakan pegawai selama priode waktu tertentu. tujuan utama penilaian kinerja adalah mengkomunikasi tujuan personal, memotivasi kinerja agar lebih baik, memberikan umpan balik konstruktif, dan menetapkan tahapan untuk rencana pengembangan yang efektif (Ma et al., 2020). Departemen sumber daya manusia dalam hal ini perlu memastikan apakah para 
pegawai diperlakukan secara baik dan apakah ada cara yang baik dan jelas untuk mengatasi keluhan. Setiap perusahaan, baik yang memiliki serikat pekerja atau tidak, memerlukan suatu cara yang tegas untuk meningkatkan kedisiplinan serta mengatasi keluhan dalam upaya mengatasi permasalahan dan melindungi tenaga kerja (Abdullah, 2017)

\section{METODE PENELITIAN}

Penelitian ini adalah penelitian kuantitatif deskriptif. Variabel dalam penelitian ini adalah sebagai berikut: 1 . Variabel Bebas (X) : Promosi Jabatan (X) dan Variabel Terikat (Y) Peningkatan Kinerja.

Populasi penelitian adalah 162 pegawai sedangkan sampel dalam penelitian ini adalah 40 responden karena diambil 25\% dari populasi. Alat analisis dalam penelitian adalah uji $\mathrm{T}$ dan uji determinasi.

\section{HASIL DAN PEMBAHASAN}

Hasil perhitungan korelasi Product Moment melalui SPSS versi 21.0 For Windows, dapat dilihat pada tabel di bawah ini:

Tabel 1. Hasil Analisis Product Moment

\begin{tabular}{cccccc}
\hline & Variabel & \multicolumn{2}{c}{ Harga $\mathbf{r}$} & \multirow{2}{*}{ Harga $\mathbf{~}^{2}$} & \multirow{2}{*}{ Keterangan } \\
Bebas & Terikat & r hitung & r tabel & Positif-signifikan \\
\hline $\mathrm{X}$ & $\mathrm{Y}$ & 0,340 & 0,297 & 0,116 & P
\end{tabular}

Dari tabel di atas dinyatakan bahwa ada hubungan positif antara promosi jabatan dengan peningkatan kinerja pegawai pada Bagian Kepegawaian Pemda Provinsi Lampung. Dari hasil analisis data di atas menunjukan korelasi Product Moment antar fasilitas kerja dengan kualitas kerja 0,340 ( $\left.\mathrm{r}_{\text {hitung }}\right)$. Dan harga koefisien determinasi $\left(\mathrm{r}^{2}\right)$ sebesar 0,116. Kemudian hasil tersebut dikonsultasikan dengan dengan $\mathrm{r}_{\text {tabel }}$ dengan taraf signifikansi $5 \%$ untuk menguji taraf signifikasinya. Harga koefisien korelasi pada $r_{\text {tabel }}$ dengan taraf signifikansi $5 \%$ dan $\mathrm{N}=40$ adalah 0,297 hasil ini menunjukkan bahwa $r_{\text {hitung }}$ lebih besar dari $r_{\text {tabel. }}$. Dengan demikian terdapat hubungan positif dan signifikan antara promosi jabatan dengan peningkatan kinerja, berarti semakin tinggi promosi jabatan maka semakintinggi pula peningkatan kinerja yang ada.

Berdasarkan penjelasan diatas bahwa hubungan positif yang dimaksud adalah adanya hubungan yang sangat kuat yang terjadi antara promosi jabatan terhadap peningkatan kinerja.

\section{KESIMPULAN}

Dari pembahasan yang telah diuraikan, maka dapat ditarik kesimpulan bahwa ada hubungan positif antara promosi jabatan dengan peningkatan kinerja pegawai pada Bagian Kepegawaian Pemda Provinsi Lampung. Dari hasil analisis data di atas menunjukan korelasi Product Moment antar fasilitas kerja dengan kualitas kerja 0,340 (rhitung). Dan harga koefisien determinasi $\left(\mathrm{r}^{2}\right)$ sebesar 0,116. Kemudian hasil tersebut dikonsultasikan dengan dengan rtabel dengan taraf signifikansi 5\% untuk menguji taraf signifikasinya. Harga koefisien korelasi pada rtabel dengan taraf signifikansi $5 \%$ dan $\mathrm{N}=40$ adalah 0,297 hasil ini menunjukkan bahwa rhitung lebih besar dari rtabel. Dengan demikian terdapat hubungan positif dan signifikan antara promosi jabatan dengan peningkatan kinerja, berarti semakin tinggi promosi jabatan maka semakin tinggi pula peningkatan kinerja yang ada.

\section{DAFTAR PUSTAKA}

Abdullah, H. (2017). Peranan Manajemen Sumberdaya Manusia Dalam Organisasi. Jurnal Warta Dharmawangsa, 51. 
Ananda, G. C. (2019). Pengaruh Penilaian Prestasi Kerja Terhadap Promosi Pegawai Pada Perguruan Panca Budi Medan. Jurnal Abdi Ilmu, 2(1), 102113.

Andriani, Y. (2018). Pengaruh Penilaian Prestasi Kerja Karyawan Terhadap Promosi Jabatan Pada Pt . Noor Asni Naga Jaya ( Rayon Ilir ) Samarida. EJurnal Administrasi Bisnis, 6(1), 1-12.

Animun, J. S. D., Sepang, J. L., \& Uhing, Y. (2017). Analisis Pelaksanaan Promosi Jabatan Dan Mutasi Berdasarkan Prestasi Kerja Karyawan Pada Pt. Bank Rakyat Indonesia (Persero), Tbk Cabang Manado. Jurnal EMBA: Jurnal Riset Ekonomi, Manajemen, Bisnis Dan Akuntansi, 5(3), 30983107. https://doi.org/10.35794/emba.v5i3.1 7374

Arifudin, Sudirman, \& Andri, M. (2017). Evaluasi Sistem Manajemen Sumber Daya Manusia Pada Penempatan Kerja Petugas Di Upt Puskesmas Lembasada. PROMOTIF: Jurnal Kesehatan Masyarakat, 7(1), 1-14. https://doi.org/10.46306/ncabet.v1i1.4

Dahlan, Hasim, D., \& Hamdan. (2017). Pengaruh Manajemen Sumber Daya Manusia dan Budaya Organisasi Terhadap Kualitas Pelayanan Pada Kantor Kecamatan Tamalate Kota Makassar. Jurnal Administrare: Jurnal Pemikiran Ilmiah Dan Pendidikan Administrasi Perkantoran, 4(2), 69-75.

Ghozali, I., Iswati, S., \& Adam, S. (2020). Pengembangan Sumber Daya Manusia Berbasis Kompetensi Sebagai Upaya Meningkatkan Kinerja Organisasi Di Pt. Pertamina Lubricant Jakarta. Ekonika : Jurnal Ekonomi Universitas Kadiri, $\quad 5(2), \quad 211$. https://doi.org/10.30737/ekonika.v5i2 .1094

Haryadi, R. N., Sunarsi, D., \& Erlangga, H. (2022). Pengaruh Promosi Jabatan Terhadap Kinerja Karyawan pada PT .
Beringin Life di Jakarta. MAMEN: Jurnal Manajemen, 1(1), 41-48.

Hasibuan, K. N., Purba, F., \& Parinduri, T. (2021). Pengaruh Penilaian Prestasi Kerja dan kompetensi Pegawai Terhadap Promosi Jabatan Pada Kantor Pelayanan Perbendaharaan Negara (KPPN) Pematangsiantar. Manajemen: Jurnal Ekonomi USI, 3(1), 75-87.

Hermawan, S., Maulana, M. R., Adinda, K., Maulana, M. T., \& Fauzan, R. M. (2020). BUKU AJAR PERLUKAH ROTASI DAN PROMOSI JABATAN? Umsida Press.

Lungguh Perceka, A. (2018). Hubungan Perencanaan dan Pengarahan Kepala Ruangan Dengan Motivasi Kerja Perawat di RS Pameungpeuk Garut Tahun 2017. Jurnal Ilmiah Administrasi Publik, 4(1), 59-65. https://doi.org/10.21776/ub.jiap.2019. 004.01 .9

Ma, E., Muin, A. N., \& Ilyas, M. F. (2020). PERAN SIKAP DAN KOMITMEN KERJA TERHADAP KINERJA PEGAWAI (STUDI KASUS PADA KANTOR DINAS ENERGI DAN SUMBER DAYA MINERAL PROVINSI SULAWESI SELATAN). MACAKKA Journal, 1(1), 267-276.

Manihuruk, C. P., \& Tirtayasa, S. (2020). Pengaruh Stres Kerja, Motivasi Kerja dan Lingkungan KerjaTerhadap Semangat Kerja Pegawai. MANEGGGIO: Jurnal Ilmiah Magister Manajemen, 3(2), 296-307.

Marlinda, T., \& Devitra, J. (2020). Analisis Dan Perancangan Sistem Informasi Layanan Pengadaan Barang Dan Jasa Berbasis Web Pada Polda Jambi. Jurnal Manajemen Sistem Informasi, 5(1), 38-48.

Muhamad Ridwan, A., Nopiyanti, E., \& Joko Susanto, A. (2018). Analisis Gejala Sick Building Syndrome Pada Pegawai Di Unit OK Rumah Sakit Marinir Cilandak Jakarta Selatan. Jukmas: Jurnal Kesehatan 
Masyarakat, 2(1), 116-133. http://ejournal.urindo.ac.id/index.php/ jukmas

Nasution, D. A. D. (2019). Pengaruh Remunerasi Dan Semangat Kerja Terhadap Kinerja Pegawai Pada Kantor Kejaksaan Negeri Medan. JURNAL AKUNTANSI DAN BISNIS : Jurnal Program Studi Akuntansi, 5(1), 71. https://doi.org/10.31289/jab.v5i1.244 1

Nurlina, N. (2020). Pengaruh Penilaian Prestasi Kerja Karyawan Terhadap Promosi Jabatan Di PT . Bank Danamon Indonesia. Jurnal Ekonomika, 4(2), 70-78. ttp://journal.1ldikti9.id/Ekonomika

Rahayu, S. (2017). Pengaruh Promosi Jabatan terhadap Kinerja Karyawan pada PT. Garuda Metalindo. Jurnal KREATIF : Pemasaran, Sumberdaya Manusia Dan Keuangan, 5(1), 59-75. http://openjournal.unpam.ac.id/index. php/kreatif/article/viewFile/701/571

Rapareni, Y. (2020). Pengaruh Promosi Jabatan dan Mutasi terhadap motivasi kerja Karyawan/ti di Divisi SDM PT PSP. Jurnal EKOBIS: Kajian Ekonomi Dan Bisnis, 3(2), 78-96.

Setiawan, A. (2018). Pengaruh Promosi Jabatan Dan Lingkungan Kerja Terhadap Semangat Kerja Pegawai Di Lingkungan Universitas Pembangunan Panca Budi Medan. Jurnal Akuntansi Bisnis Dan Publik, $8(2)$, 191-203. https://jurnal.pancabudi.ac.id/index.p $\mathrm{hp} / \mathrm{akuntansibisnisdanpublik/article/vi}$ ew/246

Sudarsana, I. K. (2016). Peningkatan Mutu Pendidikan Luar Sekolah Dalam Upayapembangunan Sumber Daya Manusia. Jurnal Penjaminan Mutu, 1(1), $\quad 1-14$. https://doi.org/10.25078/jpm.v1i1.34

Wardhani, T. E., \& Harjito, A. (2020). Peran assesment dalam promosi jabatan karyawan pada Perusahaan PT.
Sempana Pratama. Jurnal Mitra Manajemen, 11(2), 153-162.

Yusuf, N. (2018). Pengaruh Kepemimpinan, Tanggung Jawab, Kedisiplinan Dan Kerjasama Terhadap Kinerja Pegawai di Universitas Gorontalo. Gorontalo Development Review, 1(1), 15-28. https://doi.org/10.32662/golder.v1i1.1 11 